\title{
A Two-Echelon Agricultural Product Supply Chain with Freshness and Greenness Concerns: A Cost-Sharing Contract Perspective
}

\author{
Manyi Tan $\left(\mathbb{D}\right.$, Manli Tu $\mathbb{D}^{D}$, Bin Wang $\mathbb{D}^{D}$, Tianyue Zou $\mathbb{D}^{D}$, and Hong Cheng \\ College of Management Science, Chengdu University of Technology, Chengdu, China \\ Correspondence should be addressed to Hong Cheng; anne.cheng@163.com
}

Received 20 June 2020; Revised 21 August 2020; Accepted 29 September 2020; Published 19 October 2020

Academic Editor: Honglei Xu

Copyright (C) 2020 Manyi Tan et al. This is an open access article distributed under the Creative Commons Attribution License, which permits unrestricted use, distribution, and reproduction in any medium, provided the original work is properly cited.

\begin{abstract}
Agricultural products are basic needs of human beings, and whether they are cultivated in a green (or organic) manner has direct impact on environment and public health. This research incorporates product freshness and greenness into a two-echelon agricultural product supply chain (APSC). Game theoretic analyses are carried out to examine pricing, freshness, and greenness decisions of the supply chain members with and without cost-sharing for greenness investment. Subsequently, we conduct comparative and sensitivity analyses for these optimal decisions and profits of the APSC members under different cases. Numerical experiment is employed to investigate the impact of key parameters on equilibrium decisions and profitability. Analytical and experimental results show that the cost-sharing contract of greenness investment for agricultural products helps to strengthen the supply chain members' effort in improving the greenness and freshness levels of the agricultural product, thereby enhancing both individual and channel profitability of the APSC under certain conditions. This research also reveals a widened profit gap between the producer and the retailer under the cost-sharing contract.
\end{abstract}

\section{Introduction}

With continued progress of society and improvement of the standard of living, the public is increasingly concerned with soil degradation and environmental pollution due to extensive use of chemical fertilizers and pesticides in agricultural production. These environmental issues are known to pose significant threat to public health and have motivated more and more farmers to pursue organic farming and cultivate their agricultural products in a green (or organic) manner. Agricultural products in this article refer to fresh food items that are prone to microbial spoilage, ranging from fruits, vegetables, livestock, poultry, and aquatic products. Freshness of agricultural products directly affects their taste and nutrition. It has been observed that consumers are paying more attention to how agricultural products are raised and cultivated. To support sustainable development initiatives, more and more producers now promote green (or organic) modes of agricultural production. Customers are typically willing to pay a premium for fresh, green, and organic food items.
To guide and promote healthy and sustainable development of agricultural production, the first step is to properly certify green (or organic) agricultural products. Different government agencies and organizations have been actively participating in the certification process. In the marketplace, the green (or organic) characteristics of agricultural products are often highlighted to justify the premiums that are charged for these products. For example, customers can find green (or organic) signs for such agricultural products on their packaging or price tag in Walmart, Carrefour, and other supermarkets. In fact, green (or organic) is related to the production mode of agricultural products, and freshness is related to the circulation of them. Customer concerns about freshness and the green (or organic) level of agricultural products apparently affect their willingness to pay for these goods. As such, it is a worthy topic to investigate the impact of these concerns on the operations of the producers and distributors of agricultural products. This research aims to address this important problem from a supply chain management perspective. More specifically, we consider a two-echelon agricultural 
product supply chain (APSC) consisting of one producer and one retailer, where demand depends on the freshness and greenness levels of the agricultural product.

Recent years have witnessed growing interests in the APSC area, and research has been taking a variety of perspectives. For instance, aiming at cost allocation due to joint distributions of agricultural products, Wang and Jia [1] take the cost savings as income and employ a game theoretic model to solve the problem in the circulation process. By examining major large-scale agricultural cold chain logistics companies in Chongqing, China, Chen and Zhou [2] identify numerous issues that have to be addressed, ranging from improving the cold chain logistics infrastructure, establishing an information exchange platform, and building a new cold chain logistics framework catered for the Internet era. Zhu et al. [3] determine the key influencing factors of the coordination performance from such aspects as product competitiveness, communication, operations, and information-sharing capability. They then employ a fuzzy analytic hierarchy process to evaluate agricultural suppliers' synergy performance. Analytical results reveal the importance of vendor collaboration and suggest different ways to improve collaboration performance. Islam and Hoque [4] put forward a three-echelon economic batch supply chain model for agricultural product delivery. Their objective is to find out the number and size of shipments in each cycle from the supplier to the receiver so that the total cost is minimized. Jiang et al. [5] incorporate an information platform into two mathematical models for an APSC. Their results conclude that incorporation of an information platform helps to mitigate the bullwhip effect in the APSC and reduce information asymmetry between the supply chain partners. Fang et al. [6] propose a multiobjective linear programming model for green cold chain design for multiple imported fresh agricultural products in China under the Belt and Road Initiative. The objective is to balance the total cost and carbon emissions across the whole chain. In [7], the authors focus on identifying the key factors to maintain the quality and safety of agricultural products using a dynamic evolutionary game model and the multiagent modeling and simulation. Leng et al. [8] introduce an information system and RFID technology to improve the detection efficiency and food safety. The authors in [9] study on financing efficiency of Chinese agricultural listed companies and give some suggestions for them, based on machine learning.

Researchers start considering freshness of agricultural products. Cai et al. [10] take into account the impact of the level of freshness on market demand. An et al. [11] propose an agricultural product cold chain logistics management system that takes a holistic process control perspective to ensure the safety of the whole system. Yang et al. [12] establish game theoretic models to characterize safety input behavior of farmers and agroprocessing firms in an APSC. Their research shows that cooperation enhances the income of the firms compared to the noncooperative case. By assuming relatively stable demand and considering the perishable nature of agricultural products, Zheng et al. [13] examine the coordination issue in a two-echelon supply chain consisting of a retailer and a supplier where fresh- keeping effort is introduced as a decision variable. Their results demonstrate that fresh-keeping cost-sharing and revenue-sharing contracts can be employed to coordinate this supply chain. Yan et al. [14] simultaneously consider fairness concerns and freshness-keeping effort in the field of fresh agricultural product supply chain management and discuss the comparison of traditional and Nash bargaining fairness concern framework. On the other hand, Wang et al. [15] advise a carbon trading mechanism considering refrigerated logistics services in a fresh food supply chain and discuss the decisions on the price of emission permits traded within it. Liu et al. [16] treat the selection of fresh product suppliers as a multicriteria decision making (MCDM) problem and devise a two-stage fuzzy integrated MCDM approach to address this issue. Ma et al. [17] study the coordination problem of a three-echelon fresh agricultural products supply chain considering freshness-keeping effort. Yan et al. [18] improve the revenue-sharing contract to coordinate the RFID-based fresh agricultural product supply chain under the demand disruption. Yan et al. [19] character the fresh agricultural supply chain to study the optimal operational and financing strategies, and find that the level of financing by SMEs is negatively related to the freshness effort cost coefficient.

Researchers also start considering greenness of agricultural products. Zhang and Cui [20] and $\mathrm{Ma}$ et al. [17] study how to select green supplier in the agriculture supply chain, using the Bayesian network with a modified genetic algorithm and multiobjective optimization approach separately. Cui et al. [21] attempt to obtain the best stable strategy for better green technology diffusion suing evolutionary game theory. By incorporating consumers' preference for greenness, Huang et al. [22] develop four supply chain models with altruistic preferences. Then they obtain equilibrium greenness and analyse the impact of altruistic preferences on equilibrium decisions and profitability. Ghosh and Shah [23] show how greening levels, prices, and profits are influenced by channel structures and discuss the impact of greening costs and consumer sensitivity towards green apparels. Ghosh and Shah [24] explore the impact of a cost-sharing contract on the key decisions of supply chain players who undertake greening initiatives. Considering the retailer's green marketing efforts, Liu et al. [25] use revenuesharing contract to coordinate the green agricultural food supply chain.

Ehsan et al. [26] investigate the relationship between green supply chain practice and environmental performance by a case study.

This brief literature review reveals that existing research tends to treat freshness and greenness of agricultural products as two separate attributes that have not been concurrently considered in a product. But in reality, they are two inseparable attributes of agricultural products and consumers often consider them together in making their purchase decision.

Motivated by [10, 22] and Ghosh and Shah [23, 24], we introduce green (or organic) investment in a fresh APSC and devise a cost-sharing contract to improve the operations of this supply chain system. The key feature of this research is to 
incorporate both freshness and greenness concerns into the APSC. More specifically, we aim to answer the following research questions:

(i) What are the equilibrium pricing, freshness, and greenness decisions as well as resulting individual and supply chain profitability under customers' freshness and greenness concerns?

(ii) How do key model parameters, such as freshness and greenness demand sensitivity coefficients, freshkeeping effort cost parameter, green (or organic) investment cost parameter, and the cost-sharing coefficient, affect the equilibrium decisions and profitability of the APSC?

The rest of the paper is organized as follows. In Section 2, we describe the research problem and present our base APSC model under the integrated and decentralized cases. In Section 3, we establish a green (or organic) investment cost-sharing model to enhance operations of the supply chain and improve the freshness and greenness levels of the agricultural product. Section 4 discusses the impacts of key parameters on equilibrium decisions and profitability of the APSC by using numerical analyses. Finally, the Conclusions section concludes this research and points out directions for future research.

\section{Problem Description and the Base Model under the Integrated and Decentralized Cases}

The green (or organic) refers to the control of production mode and production process to make agricultural product pollution-free and ensure its safety, quality, and nutrition, and the organic emphasizes the natural nature of agricultural products especially; this is related to the green (or organic) investments of producers. On the other hand, agricultural products have a certain shelf life, and the fresh refers to the agricultural products to keep water and nutrition, and prevent corruption and deterioration; this is related to the retailer's efforts to keep fresh.

We consider a two-stage APSC with one producer and one retailer. The producer produces one green product and makes decisions based on the principle of profit maximization. The product is sold to the retailer at a unit wholesale price, and the retailer keeps the product fresh and sells it to consumers at a unit retail price. All the notations in the base supply chain model here and the extended model in Section 2 are shown in Table 1.

With continued improvement of standards of living, consumers are increasingly concerned about the freshness and greenness levels of agricultural products. The freshness level depends on the retailer's freshness-keeping effort he should invest during the transportation and storage process. The greenness level depends on the producer's greenness-keeping effort he should invest during the producing process. Following the similar treatment in [10], Ghosh and Shah [23,24], and Cui et al. [27], we assume that consumer demand increases in both the freshness (characterized by a decision variable $\theta$ ) and the greenness (depicted by a decision variable $\mu$ ) levels of the agricultural product. To make the model tractable, we model the impact of agricultural product pricing, freshness, and greenness levels on consumer demand in a deterministic form as

$$
q=\alpha-b p+\tau \theta+\beta \mu .
$$

In equation (1), $\alpha, b, \tau, \beta>0$, and $\mu$ and $\theta$ are, respectively, two continuous decision variables to characterize the greenness and freshness levels of the agricultural product. The bigger the $\tau(\beta)$ is, the more sensitive the consumers are for the freshness (greenness) level of the agricultural product, and the market will have more demand for the agricultural product if other parameters are kept constant.

Both the retailer and producer benefit from enhanced demand when agricultural products are fresher and greener. The producer incurs the green (or organic) investment cost. Following Liu et al. [25], Sacco and De Giovanni [10, 28], Ghosh and Shah [23, 24], and Cui et al. [27], we assume quadratic cost functions of the efforts. The producer's marginal production cost is independent of the greenness level of the agricultural product, but investment in greenness of the agricultural product incurs a quadratic cost $(1 / 2) \lambda \mu^{2}$, where $\lambda$ is the green (or organic) investment parameter. Similarly, the retailer incurs the fresh-keeping effort cost, and the cost function is assumed to have the same quadratic form as $(1 / 2) k \theta^{2}$, where $k$ is the fresh-keeping effort cost parameter. Our assumption that these costs are quadratic and independent of the production quantity is widely adopted in the literature to characterize different efforts such as corporate social responsibility investment [29] and marketing effort [30]. These assumptions specify how sensitive the producer's green (or organic) investment cost is to the greenness level of the agricultural product and how sensitive the retailer's fresh-keeping cost is to its freshness level. It is apparent that the higher the value $\lambda(k)$, the higher the cost the producer (retailer) incurs to produce (keep) the agricultural product at a given greenness (freshness) level.

In our base model, the cost of green (or organic) investment is only borne by the producer and the freshkeeping effort cost is incurred by the retailer. Based on the aforesaid model assumptions, the profit functions of the producer and the retailer in the decentralized case are given as

$$
\begin{aligned}
& \prod_{P}^{D}=(w-c) q-\frac{1}{2} \lambda \mu^{2}, \\
& \prod_{R}^{D}=(p-w) q-\frac{1}{2} k \theta^{2},
\end{aligned}
$$

where $c$ is the base unit production cost of the agricultural product. The subscripts $P$ and $R$ represent the producer and the retailer, respectively. On the other hand, the integrated supply chain's profit function is given by 
TABLE 1: The notations in the APSC decision models.

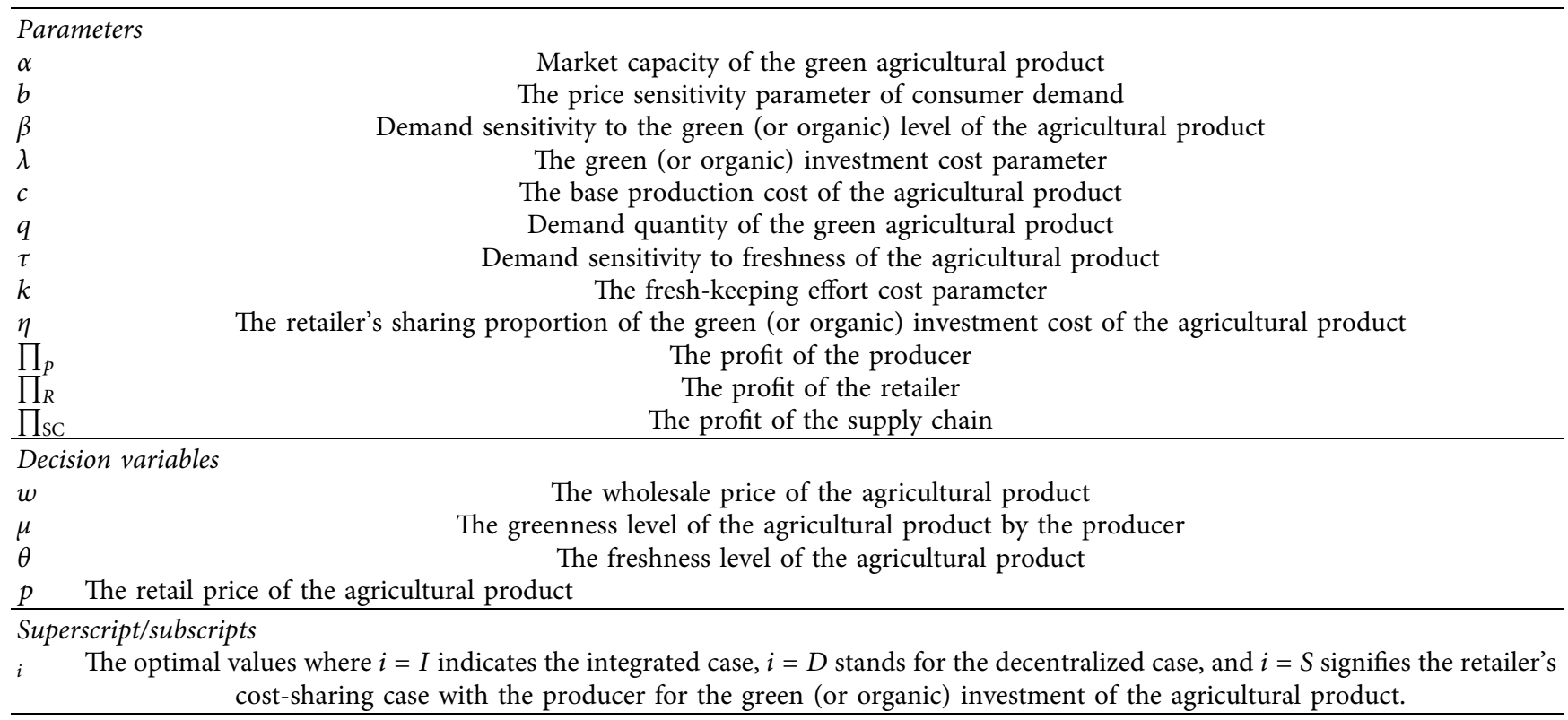

$$
\prod_{\mathrm{SC}}^{I}=(p-c) q-\frac{1}{2} \lambda \mu^{2}-\frac{1}{2} k \theta^{2}
$$

Here, the superscript I specifies the integrated case and the subscript SC signifies the supply chain profit. In the decentralized case, the two APSC members play a Stackelberg game and the producer is modeled as the leader. Solving this Stackelberg problem by inverse induction methods, such as the research by Zheng et al. [31], we obtain the equilibrium freshness and greenness levels, and wholesale and retail prices as well as individual and supply chain profitability as shown in the third column in Table 2. For the integrated case, by the first-order conditions, we obtain the optimal retail price, freshness, and greenness decisions as well as the supply chain profit as shown in the second column in Table 2. To make the equilibrium solutions meaningful, we assume that $2 b k>\tau^{2}, \alpha-b c>0$, and $2 b k \lambda-\beta^{2} k>\lambda \tau^{2}$.

\section{A Greenness Investment Cost-Sharing Contract for Improving APSC Operations}

It has been observed that consumers are increasingly interested in fresh, green (or organic) agricultural products for health and environmental concerns. As mentioned before, both the retailer and the producer benefit from enhanced market demand owing to heightened freshness and greenness levels of the agricultural product. However, our base model in Section 2 assumes that the producer is solely responsible for the increased investment cost for improving the green (or organic) level of the agricultural product. It is understandable that the producer may feel unfair and require the retailer to pull its weight. Otherwise, the producer's fairness concerns can dampen its effort in investing in improving the green/organic level. Hence, to furnish the producer with proper incentive, a well-conceived investment cost-sharing contract can play an important role. Next, we shall employ this tool to answer the following questions:

(i) When the retailer is willing to share a proportion of the green (or organic) investment cost with the producer, what is the impact on their equilibrium pricing, freshness, and greenness decisions?

(ii) Will both the retailer and the producer benefit in profitability by the cost-sharing contract?

To address these issues, we build another Stackelberg game model, where the producer remains the leader. Under this game structure, when the retailer offers to share $\eta$ proportion of the green (or organic) investment cost incurred by the producer, the two supply chain members' profit functions are given as

$$
\begin{gathered}
\prod_{P}^{S}=(w-c) q-\frac{1}{2}(1-\eta) \lambda \mu^{2}, \\
\prod_{R}^{S}=(p-w) q-\frac{1}{2} k \theta^{2}-\frac{1}{2} \eta \lambda \mu^{2} .
\end{gathered}
$$

For the decentralized model in equations (4) and (5), to better motivate the producer to invest in the green (or organic) level and enhance demand of the agricultural product, the retailer offers to share a proportion of this investment cost. It should be noted that this cost-sharing behavior is quite common in supply chain management for the collective betterment. The decision sequence is as follows: the producer as the Stackelberg leader first chooses the green (or organic) level $(\mu)$ of the agricultural product and its wholesale price $(w)$. Then, the retailer as the follower decides its retail price and the freshness degree $(\theta)$ for the green agricultural product. Both members are profitmaximizers.

According to the steps of the reverse recursive method, the existence of the optimal value of the profit function is 
TABLE 2: Equilibrium solutions under the integrated and decentralized cases.

\begin{tabular}{lcc}
\hline Optimal & Integrated case (I) & Decentralized case (D) \\
\hline$p$ & $p^{I}=\left(b c k \lambda-\beta^{2} c k-c \lambda \tau^{2}+\alpha k \lambda\right) /\left(2 b k \lambda-\beta^{2} k-\lambda \tau^{2}\right)$ & $p^{D}=\left(b^{2} c k \lambda-b \beta^{2} c k-b c \lambda \tau^{2}+3 \alpha b k \lambda-\alpha \lambda \tau^{2}\right) /\left(\left(4 b k \lambda-\beta^{2} k-2 \lambda \tau^{2}\right) b\right)$ \\
$w$ & - & $w^{D}=\left(2 b^{2} c k \lambda-b \beta^{2} c k-b c \lambda \tau^{2}+2 \alpha b k \lambda-\alpha \lambda \tau^{2}\right) /\left(\left(4 b k \lambda-\beta^{2} k-2 \lambda \tau^{2}\right) b\right)$ \\
$\mu$ & $\mu^{I}=(\beta k(-b c+\alpha)) /\left(2 b k \lambda-\beta^{2} k-\lambda \tau^{2}\right)$ & $\mu^{D}=(\beta k(-b c+\alpha)) /\left(4 b k \lambda-\beta^{2} k-2 \lambda \tau^{2}\right)$ \\
$\theta$ & $\theta^{I}=(\lambda(-b c+\alpha) \tau) /\left(2 b k \lambda-\beta^{2} k-\lambda \tau^{2}\right)$ & $\theta^{D}=((-b c+\alpha) \lambda \tau) /\left(4 b k \lambda-\beta^{2} k-2 \lambda \tau^{2}\right)$ \\
$\prod_{P}$ & - & $\Pi_{P}^{D}=\left((-b c+\alpha)^{2} k \lambda\right) /\left(2\left(4 b k \lambda-\beta^{2} k-2 \lambda \tau^{2}\right)\right)$ \\
$\prod_{R}$ & $\Pi_{S C}^{I}=\left(k \lambda(-b c+\alpha)^{2}\right) /\left(2\left(2 b k \lambda-\beta^{2} k-\lambda \tau^{2}\right)\right)$ & $\Pi_{S C}^{D}=\left((-b c+\alpha)^{2} k \lambda\left(6 b k \lambda-\beta^{2} k-3 \lambda \tau^{2}\right)\right) /\left(2\left(4 b k \lambda-\beta^{2} k-2 \lambda \tau^{2}\right)^{2}\right)$ \\
\hline$\prod_{S C}$ & $\Pi_{R}^{D}=\left(\left(k^{2}(-b c+\alpha)^{2}\left(2 b k-\tau^{2}\right)\right) / 2\left(4 b k \lambda-\beta^{2} k-2 \lambda \tau^{2}\right)^{2}\right.$ \\
\hline
\end{tabular}

determined by the Hessian matrix, and the equilibrium decisions can be obtained by using the first-order condition. All results under the cost-sharing model are shown in Table 3.

By comparing the optimal solutions in Tables 2 and 3, we can obtain the following propositions:
Proposition 1. If $\left(\eta<\beta^{2} k\left(4 \lambda k b-k \beta^{2}-2 \tau^{2} \lambda\right)\right) /(\lambda$ $\left.\left(2 k b-\tau^{2}\right)\left(8 \lambda k b-k \beta^{2}-4 \tau^{2} \lambda\right)\right)(<1 / 2), \quad \prod_{R}^{S}-\prod_{R}^{D}>0$, $\prod_{P}^{S}-\prod_{P}^{D}>0$.

Proof. Let

$B=16 b^{2} k^{2} \lambda^{2}-2 \beta^{2} b k^{2} \lambda-16 b k \lambda^{2} \tau^{2}+\beta^{2} k \lambda \tau^{2}+4 \lambda^{2} \tau^{4}$, then

$$
\begin{aligned}
& \prod_{R}^{S}-\prod_{R}^{D}=-\frac{\beta^{2}(-b c+\alpha)^{2} \lambda k^{2}\left(B \eta-4 b \beta^{2} k^{2} \lambda+\beta^{4} k^{2}+2 \beta^{2} k \lambda \tau^{2}\right) \eta}{2\left(-2 \tau^{2} \lambda+4 \lambda k b-k \beta^{2}\right)^{2}\left(4 b \eta k \lambda-2 \eta \lambda \tau^{2}-4 \lambda k b+k \beta^{2}+2 \tau^{2} \lambda\right)^{2}} \\
& \prod_{P}^{S}-\prod_{P}^{D}=\frac{-k^{2} \lambda \beta^{2} \eta(b c-\alpha)^{2}}{32\left(\left(b k-1 / 2 \tau^{2}\right) \lambda-1 / 4 \beta^{2} k\right)\left((\eta-1)\left(b k-1 / 2 \tau^{2}\right) \lambda+1 / 4 \beta^{2} k\right)}
\end{aligned}
$$

Obviously, when the specified conditions are met, the conclusion holds.

Proposition 1 shows that, when the retailer offers to share the producer's investment in improving the green (or organic) level of the agricultural product, both members can improve their profitability as long as the sharing proportion is not too excessive. This result is sensible as the retailer will directly benefit from an enhanced greenness level and its sharing of the greenness investment will motivate the producer to put more effort in improving the greenness level of the agricultural product, thereby leading to a win-win scenario for both supply chain members. This win-win scenario provides the retailer with the incentive to share with the producer the green (or organic) investment cost.
Proof. $\Pi_{\mathrm{SC}}^{I}-\Pi_{\mathrm{SC}}^{S}>0$ $2 b \eta^{2} k \lambda+3 \beta^{2} \eta^{2} k-\eta^{2} \lambda \tau^{2}-4 b \eta k \lambda-2 \beta^{2}$ $\eta k+2 \eta \lambda \tau^{2}+2 b k \lambda-\lambda \tau^{2}>0$.

Because the left-hand side of the aforesaid inequality is a quadratic polynomial with respect to $\eta$, let $A=2 b k \lambda+3 \beta^{2} k-\lambda \tau^{2}, \quad \Delta=\left(-4 b k \lambda-2 \beta^{2} \eta k+2 \lambda \tau^{2}\right)^{2}$ $-4\left(2 b k \lambda+3 \beta^{2} k-\lambda \tau^{2}\right)\left(2 b k \lambda-\lambda \tau^{2}\right)$. According to our assumptions, $A>0, \Delta<0$. So, it is confirmed that

$$
\begin{aligned}
& \eta^{2}\left(2 b k \lambda+3 \beta^{2} k-\lambda \tau^{2}\right)+\eta\left(2 \lambda \tau^{2}-4 b k \lambda-2 \beta^{2} \eta k\right) \\
& +2 b k \lambda-\lambda \tau^{2}>0 .
\end{aligned}
$$

On the other hand,

Proposition 2. $\prod_{S C}^{I}>\prod_{S C}^{S}>\prod_{S C}^{D}$.

$$
\prod_{\mathrm{SC}}^{D}-\prod_{\mathrm{SC}}^{S}=\frac{-\eta\left(b k-(1 / 2) \tau^{2}\right)\left((\eta-(1 / 2))\left(b k-(1 / 2) \tau^{2}\right) \lambda-(3 / 16) k(\eta-(2 / 3)) \beta^{2}\right) \lambda^{2} k^{2}(b c-\alpha)^{2} \beta^{2}}{16\left(\left(b k-(1 / 2) \tau^{2}\right) \lambda-(1 / 4) \beta^{2} k\right)^{2}\left(\left(b k-(1 / 2) \tau^{2}\right)(\eta-1) \lambda+(1 / 4) \beta^{2} k\right)^{2}}<0
$$

and this proposition is proved.

Proposition 2 demonstrates that, if the retailer is willing to share the producer's green (or organic) investment cost, the supply chain profit will be enhanced compared to the case when the investment cost is solely borne by the producer under the decentralized case. It is natural that the supply chain profit under the cost-sharing contract generally underperforms the integrated case when both members are fully coordinated. This result indicates that the retailer's cost-sharing cannot fully coordinate the APSC but help to 
TABLE 3: Equilibrium decisions and profitability under the cost-sharing model.

\begin{tabular}{lc}
\hline Cost-sharing contract $(S)$ & \\
\hline$p^{S}$ & $\left(\left(b^{2} c k+\left(-c \tau^{2}+3 \alpha k\right) b-\tau^{2} \alpha\right)(\eta-1) \lambda+b \beta^{2} c k\right) /\left(4 b\left(\left(b k-(1 / 2) \tau^{2}\right)(\eta-1) \lambda+(1 / 4) \beta^{2} k\right)\right)$ \\
$w^{S}$ & $\left(2\left(\left(b k-(1 / 2) \tau^{2}\right)\right)(b c+\alpha)(\eta-1) \lambda+b \beta^{2} c k\right) /\left(4 b\left(\left(b k-(1 / 2) \tau^{2}\right)(\eta-1) \lambda+(1 / 4) \beta^{2} k\right)\right)$ \\
$\mu^{S}$ & $-\beta k(-b c+\alpha) / 4\left(\left(b k-(1 / 2) \tau^{2}\right)\right)(\eta-1) \lambda+\beta^{2} k$ \\
$\theta^{S}$ & $(\alpha-b c)(\eta-1) \lambda \tau /\left(4\left(b k-(1 / 2) \tau^{2}\right)(\eta-1) \lambda+\beta^{2} k\right)$ \\
$\prod_{P}^{S}$ & $\left((b c-\alpha)^{2}(\eta-1) k \lambda\right) /\left(8\left(b k-(1 / 2) \tau^{2}\right)(\eta-1) \lambda+2 \beta^{2} k b k\right)$ \\
$\prod_{R}^{S}$ & $\left(k \lambda\left(\left(b k-(1 / 2) \tau^{2}\right)(\eta-1)^{2} \lambda-\left(1 / 2 k \eta \beta^{2}\right)\right)(b c-\alpha)^{2}\right) /\left(16\left(\left(b k-(1 / 2) \tau^{2}\right)(\eta-1) \lambda+(1 / 4) \beta^{2} k\right)^{2}\right)$ \\
$\prod_{S C}^{S}$ & $\left(3 \lambda\left(\left(b k-(1 / 2) \tau^{2}\right)(\eta-1)^{2} \lambda-(1 / 6) \beta^{2} k\right) k(b c-\alpha)^{2}\right) /\left(16\left(\left(b k-(1 / 2) \tau^{2}\right)(\eta-1) \lambda+(1 / 4) \beta^{2} k\right)^{2}\right)$ \\
\hline
\end{tabular}

enhance channel profitability, which has important impli- Proof.

cations for better operating the supply chain.

Proposition 3. $\prod_{P}^{D}>\prod_{R}^{D}, \prod_{P}^{S}>\prod_{R}^{S}$.

$$
\begin{aligned}
& \prod_{P}^{D}-\prod_{R}^{D}=\frac{k \lambda(-b c+\alpha)^{2}\left(2 b k \lambda-\beta^{2} k-\lambda \tau^{2}\right)}{2\left(4 b k \lambda-\beta^{2} k-2 \lambda \tau^{2}\right)^{2}}, \\
& \prod_{P}^{S}-\prod_{R}^{S}=\frac{k(-b c+\alpha)^{2}\left(2 b \eta^{2} k \lambda-\eta^{2} \lambda \tau^{2}-4 b \eta k \lambda+2 \beta^{2} \eta k+2 \eta \lambda \tau^{2}+2 b k \lambda-\beta^{2} k-\lambda \tau^{2}\right) \lambda}{2\left(4 b \eta k \lambda-2 \eta \lambda \tau^{2}-4 b k \lambda+\beta^{2} k+2 \lambda \tau^{2}\right)^{2}} .
\end{aligned}
$$

Let $f(\eta)=\left(2 b k \lambda-\lambda \tau^{2}\right) \eta^{2}+\left(-4 b k \lambda+2 \beta^{2} k+2 \lambda \tau^{2}\right) \eta+$ $2 b k \lambda-\beta^{2} k-\lambda \tau^{2}$ and $A=2 b k \lambda-\lambda \tau^{2}>0$, then

$$
\begin{aligned}
\Delta & =-8 b \beta^{2} k^{2} \lambda+4 \beta^{4} k^{2}+4 \beta^{2} k \lambda \tau^{2} \\
& =-4 \beta^{2} k\left(2 b k \lambda-\beta^{2} k-\lambda \tau^{2}\right)<0 .
\end{aligned}
$$

So, $f(\eta)>0, \prod_{P}^{S}-\prod_{R}^{S}>0$.

The proposition reveals that for the producer-dominated APSC with freshness and greenness concerns, the producer as the Stackelberg leader always achieves a higher profit than the retailer does. This is true regardless of whether the retailer shares the green (or organic) investment cost incurred by the producer.

Proposition 4. $\prod_{P}^{D}-\prod_{R}^{D} \leq \prod_{P}^{S}-\prod_{R}^{S}$.

$$
\begin{array}{r}
A=2 b \beta^{2} \eta k^{2} \lambda-\beta^{2} \eta k \lambda \tau^{2}+16 b^{2} k^{2} \lambda^{2}-12 b \beta^{2} k^{2} \lambda-16 b k \lambda^{2} \tau^{2}+2 \beta^{4} k^{2}+6 \beta^{2} k \lambda \tau^{2}+4 \lambda^{2} \tau^{4} \\
\left(\prod_{P}^{D}-\prod_{R}^{D}\right)-\left(\prod_{P}^{S}-\prod_{R}^{S}\right)=\frac{-A k^{2} \lambda(-b c+\alpha)^{2} \beta^{2} \eta}{2\left(4 b k \lambda-\beta^{2} k-2 \lambda \tau^{2}\right)^{2}\left(4 b \eta k \lambda-2 \eta \lambda \tau^{2}-4 b k \lambda+\beta^{2} k+2 \lambda \tau^{2}\right)^{2}}
\end{array}
$$

By rearranging the expression in $A$, we have $A=\beta^{2} k\left(2 b k \lambda-\lambda \tau^{2}\right) \eta+2\left(2 b k \lambda-\beta^{2} k-\lambda \tau^{2}\right)$ $\left(4 b k \lambda-\beta^{2} k-2 \lambda \tau^{2}\right)$. Since $\eta \geq 0$, according to our assumptions, $A>0$ and this proposition is thus proved.

Proposition 4 indicates that the retailer's sharing of the producer's green (or organic) investment cost will further widen the profit gap between the two members in the producer-dominated APSC with freshness and greenness concerns. This is reasonable as the producer grabs a larger share of the channel profit without cost-sharing (Proposition 3) due to the first-mover advantage, and the retailer's sharing of the greenness investment cost will further enhance the producer's first-mover advantage and lead to a widened profit gap between the producer and the retailer.
Proposition 5. $w, \mu, p$, and $\theta$, and $\Pi_{P}, \Pi_{R}$, and $\Pi_{S C}$ all decrease monotonously in the cost parameter $\lambda$ and $k$ under the integrated, decentralized, and cost-sharing cases.

Proof. By examining the first-order partial derivatives of decision variables and profit functions with respect to $\lambda$ and $k$, Proposition 5 can be easily proved.

Note that parameters $\lambda$ and $k$ stand for the cost parameters of greenness and freshness investment of the agricultural product, respectively. This proposition demonstrates that all equilibrium pricing and effort decisions and profit functions in the APSC under the three cases are monotonously decreasing in these two cost parameters. Taking the greenness cost parameter $\lambda$ as an example, a higher $\lambda$ indicates that it is more expensive for the producer 
or the central planner to provide green (or organic) agricultural products to the market. This heightened cost inevitably dampens the supply chain members' effort levels and reduces their pricing power, which is eventually translated into lower individual and channel profitability. The same interpretation is applicable to the fresh-keeping cost parameter $k$.

Proposition 6. $w, \mu, p$, and $\theta$, and $\Pi_{P}, \Pi_{R}$, and $\Pi_{S C}$ all increase monotonously in the demand sensitivity parameters $\tau$ and $\beta$ under the integrated, decentralized, and cost-sharing cases.

Proof. By checking the first-order partial derivatives of decision variables and profit functions with respect to $\tau$ and $\beta$, one can prove Proposition 6.

Recall that parameters $\tau$ and $\beta$ represent how sensitive market demand is to the freshness and greenness of the agricultural product. The greater the parameter values $\tau$ and $\beta$, the more sensitive the customer demand is for the freshness and greenness of the agricultural product. More sensitive consumer demand motivates the supply chain members to exert more effort, thereby allowing them to charge higher prices and achieving higher individual and channel profitability.
Proposition 7. $p^{S}, w^{S}, \mu^{S}, \theta^{S}$, and $\Pi_{P}^{S}$ increase in the costsharing ratio $\eta$.

Proof. By obtaining the first-order partial derivatives of decision variables and profit functions with respect to $\eta$, Proposition 7 can be easily proved.

When the retailer offers to share a proportion of the producer's greenness investment cost, a higher cost-sharing ratio shows the retailer's more willingness to contribute to the collective betterment and motivates both supply chain members to put more effort in enhancing the freshness and greenness of the agricultural product, thereby enhancing their pricing power. This eventually leads to a higher profit for the producer. However, for the impact of a higher costsharing ratio on the profits of the retailer and channel, it is more complicated as shown in Figure 1 in the numerical experiment in Section 4: they first increase in $\eta$ but turn lower when this cost-sharing ratio is excessive.

Proposition 8. $\mu^{D}<\mu^{S}, \theta^{D}<\theta^{S}$ and $w^{D}<w^{S}, p^{D}<p^{S}$.

Proof. $\mu^{D}-\mu^{S}=\left(-k \lambda \beta\left(b k-(1 / 2) \tau^{2}\right) \quad(b c-\alpha) \eta\right) /(4((b k-$ $\left.\left.\left.(1 / 2) \tau^{2}\right) \lambda-(1 / 4) \beta^{2} k\right)\left(\left(b k-(1 / 2) \tau^{2}\right)(\eta-1) \lambda+(1 / 4) \beta^{2} k\right)\right)$.

$$
\begin{gathered}
\theta^{D}-\theta^{S}=\frac{-\lambda \tau \beta^{2} \eta k(b c-\alpha)}{16\left(\left(b k-(1 / 2) \tau^{2}\right) \lambda-(1 / 4) \beta^{2} k\right)\left(\left(b k-(1 / 2) \tau^{2}\right)(\eta-1) \lambda+(1 / 4) \beta^{2} k\right)}, \\
w^{D}-w^{S}=\frac{-(b c-\alpha)\left(b k-(1 / 2) \tau^{2}\right) k \beta^{2} \lambda \eta}{8\left(\left(b k-(1 / 2) \tau^{2}\right) \lambda-(1 / 4) \beta^{2} k\right)\left(\left(b k-(1 / 2) \tau^{2}\right)(\eta-1) \lambda+(1 / 4) \beta^{2} k\right) b}, \\
p^{S}-p^{D}=\frac{3(b c-\alpha)\left(b k-(1 / 3) \tau^{2}\right) k \beta^{2} \lambda \eta}{16\left(\left(b k-(1 / 2) \tau^{2}\right)(\eta-1) \lambda+(1 / 4) \beta^{2} k\right) b\left(\left(b k-(1 / 2) \tau^{2}\right) \lambda-(1 / 4) \beta^{2} k\right)} .
\end{gathered}
$$

According to our assumptions, these results in Proposition 8 are confirmed.

Proposition 8 indicates that the retailer's sharing of the producer's green (or organic) investment cost motivates the producer to produce agricultural products at a higher greenness level, which in turn encourages the retailer to enhance its freshness level. Subsequently, the producer and the retailer are able to charge higher wholesale and retail prices for the fresher and greener agricultural product compared to the decentralized case without cost-sharing.

\section{Numerical Studies}

In this section, we shall conduct numerical experiment to examine the impact of key model parameters on equilibrium decisions and supply chain profit. The parameters considered here include demand sensitivity to the freshness level $(\tau)$, demand sensitivity to the greenness level $(\beta)$, the retailer's fresh-keeping cost coefficient $(k)$, the producer's green (or organic) investment cost coefficient $(\lambda)$, and the retailer's cost-sharing proportion $(\eta)$ of the producer's green (or organic) investment cost. In the following numerical experiment, we assume that the market capacity of the agricultural product $\alpha=1000$, price sensitivity parameter of the demand function $b=8$, and the base unit production cost $c=4$.

4.1. Impact of Key Parameters on Individual Profits in the APSC under Different Cases. By assuming $\eta=0.15$, based on the equilibrium results in Tables 2 and 3, we can plot the two members' individual profits in the APSC against various parameters under the two decentralized cases with and without cost-sharing in Figure 2. Figures 2(a) and 2(b) confirm Proposition 6 that individual profits in the APSC are positively correlated with the two demand sensitivity parameters $\beta$ and $\tau$. For small cost-sharing ratios (at $\eta=0.15$ in this case), Figures 2(a) and 2(b) also demonstrate that both members are better off in profitability under the cost-sharing case than the decentralized 


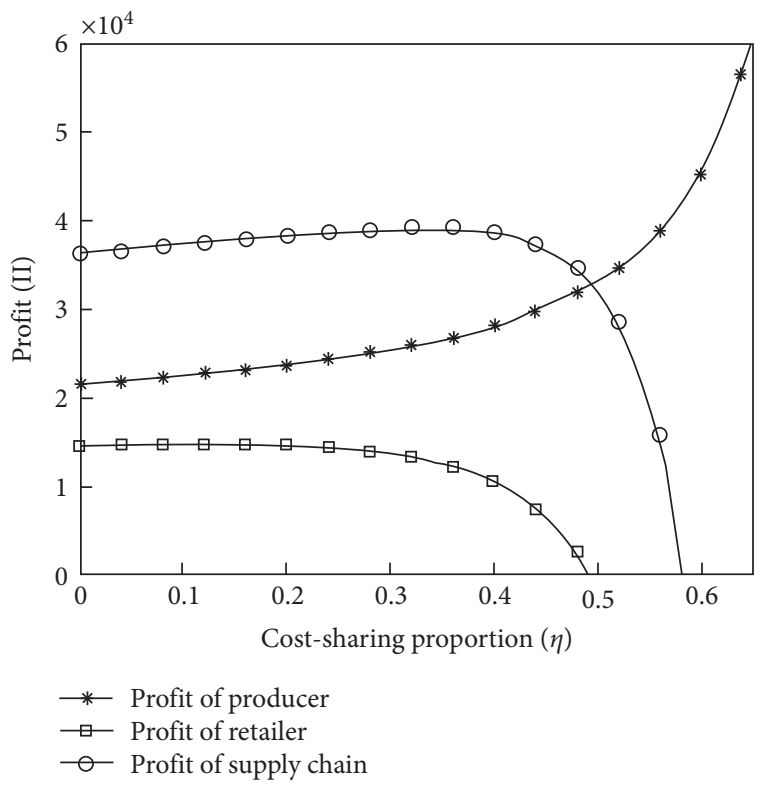

FIGURE 1: Impact of the cost-sharing proportion $(\eta)$ on individual and channel profits.

case without cost-sharing (Proposition 1). When consumers are more sensitive to the greenness and freshness levels of the agricultural product, both supply chain members can capitalize on the enhanced demand to rake in more profits. Given this set of parameter values, the existence of the equilibrium solutions requires that $\lambda>15.46$. Under the conditions that equilibrium solutions exist, Figures 2(c) and 2(d) confirm the negative correlations between individual profits and these two cost parameters (See Proposition 5), indicating that both members' individual profits (and, subsequently, the channel profit) will suffer if it is more expensive for the producer to produce green (or organic) agricultural product and for the retailer to keep it fresh. Furthermore, Figures 2(a)-2(d) also verify Propositions 3 and 4: both members achieve higher profits under the cost-sharing case than the decentralized case without cost-sharing (Proposition 3) and the profit gaps between the producer and retailer under the cost-sharing case are wider than those under the decentralized case without cost-sharing (Proposition 4).

4.2. Impact of the Cost-Sharing Proportion ( $\eta$ ) on Individual and Channel Profits. By setting $\lambda=30, k=25, \tau=6$, and $\beta=15$, we plot individual and channel profits against the cost-sharing proportion $\eta$ as shown in Figure 1. The retailer's offer of sharing the investment cost will reduce the burden of the producer who is motivated to improve the green (or organic) level of the agricultural product. Figure 1 confirms that, when the cost-sharing ratio $\eta$ increases, the producer always enjoys a higher profit (see Proposition 7). On the other hand, the retailer's profit and the channel profit first increase in the cost-sharing ratio $\eta$ and, then, start declining after they reach their maxima. It is worth noting that the channel profit always reaches its maximum at a larger costsharing ratio $\eta$ compared to the case when the retailer's profit attains its maximum. This is understandable as the producer always gains from a higher cost-sharing ratio while the retailer will suffer when the ratio is beyond the optimal level. The channel profit starts declining at a larger $\eta$ when the producer's profit enhancement is unable to cover the retailer's profit reduction.

4.3. Impact of Key Parameters on the Retail Prices ( $p$ ) under Different Cases. Let $\eta=0.15$. Figure 3 plots the retail price as a function of the four key model parameters. More specifically, Figures 3(a) and 3(b) show that the retailer can charge a higher retail price (thereby gaining more profit as shown in Figures 2(a) and 2(b)) when consumers are more sensitive to the greenness and freshness levels of the agricultural product at higher $\beta$ and $\tau$ values (see Proposition 6) that enhance demand more dramatically. Under the basic linear demand function without greenness or freshness concerns $\beta=\tau=0$, Figures 3(a) and 3(b) indicate that the integrated case is most efficient and allows the central planner to charge the lowest retail price, and the cost-sharing case has the highest retail price as the retailer charges a higher price than the decentralized case without cost-sharing to pass part of the increased expense onto consumers. When market demand is more sensitive to consumers' greenness and freshness concerns at higher $\beta$ and $\tau$, the most efficient integrated channel is able to capitalize on much heightened demand and charge the highest retail price as shown in the sharply increased solid curves in Figures 3(a) and 3(b). On the other hand, the retail price under the cost-sharing case remains larger than the decentralized case without costsharing as attested in Proposition 8. Conversely, Figures 3(c) and 3(d) illustrate the impact on the retail price by the two cost-side parameters $\lambda$ and $k$ instead of the benefit-side (demand-enhancing) parameters $\beta$ and $\tau$. Their interpretations follow the same line of thinking, but the relevant relations are reversed. For instance, the retail price of the agricultural product decreases in these two cost parameters as given in Proposition 5. Higher values of $\lambda$ and $k$ signify more significant barriers for the supply chain members to improve the greenness and freshness levels of the agricultural product, thereby compressing demand and leading to lower retail prices. Similarly, at the lower end of these two cost parameters, Figures 3(c) and 3(d), the integrated case has the highest retail price and the decentralized case has the lowest while the cost-sharing case falls in-between. At sufficiently large $\lambda$ and $k$, the integrated case suffers the largest drop and turns to the lowest level among the three cases. On the other hand, the relative positions of the retail prices under the cost-sharing and decentralized cases remain intact as shown in the figures and confirmed by Proposition 8.

The impact of key parameters on the wholesale prices $(w)$ under the decentralized and cost-sharing cases is similar to those of retail prices $(p)$ with the same situations. The figure and its interpretations are omitted. 

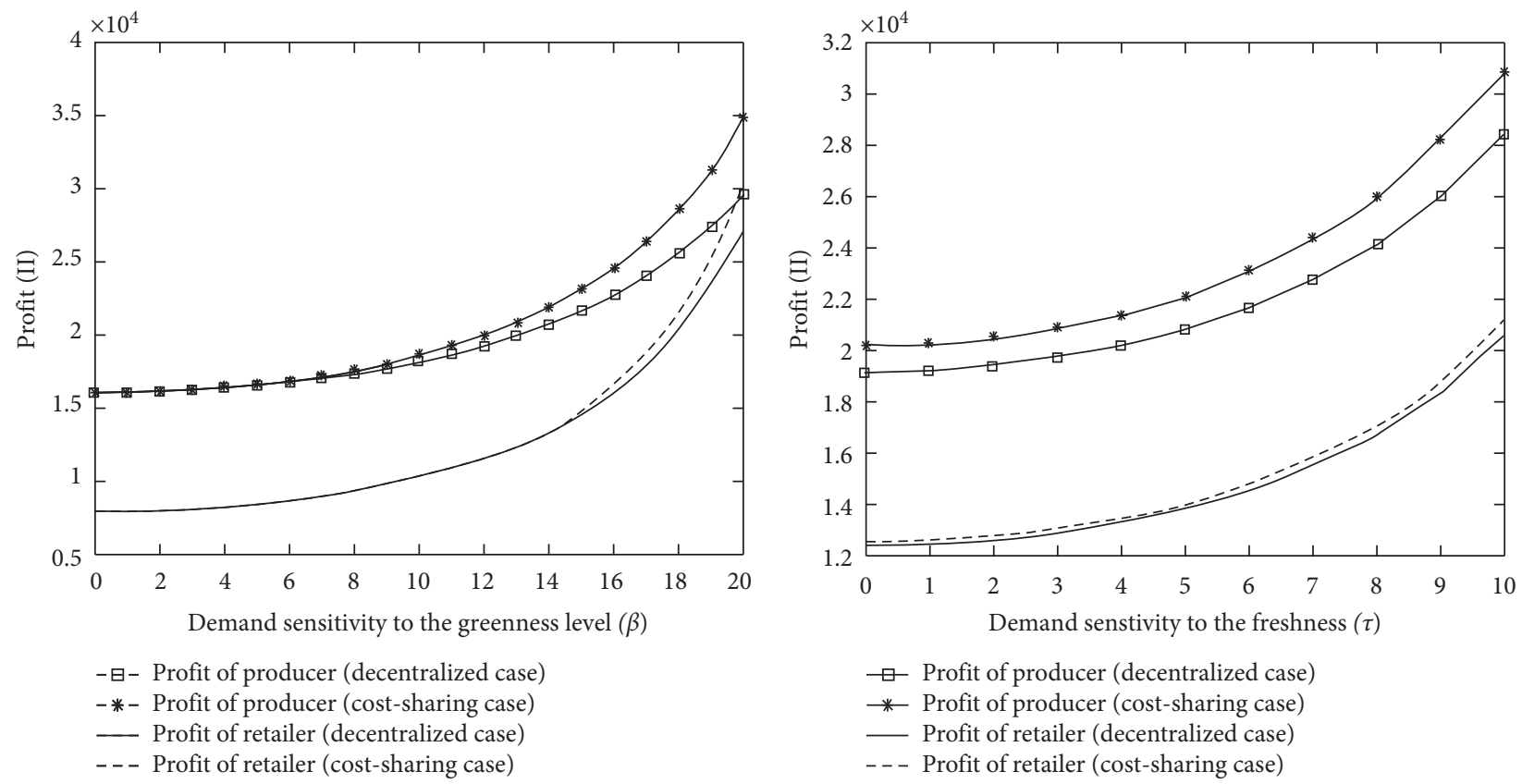

(b)

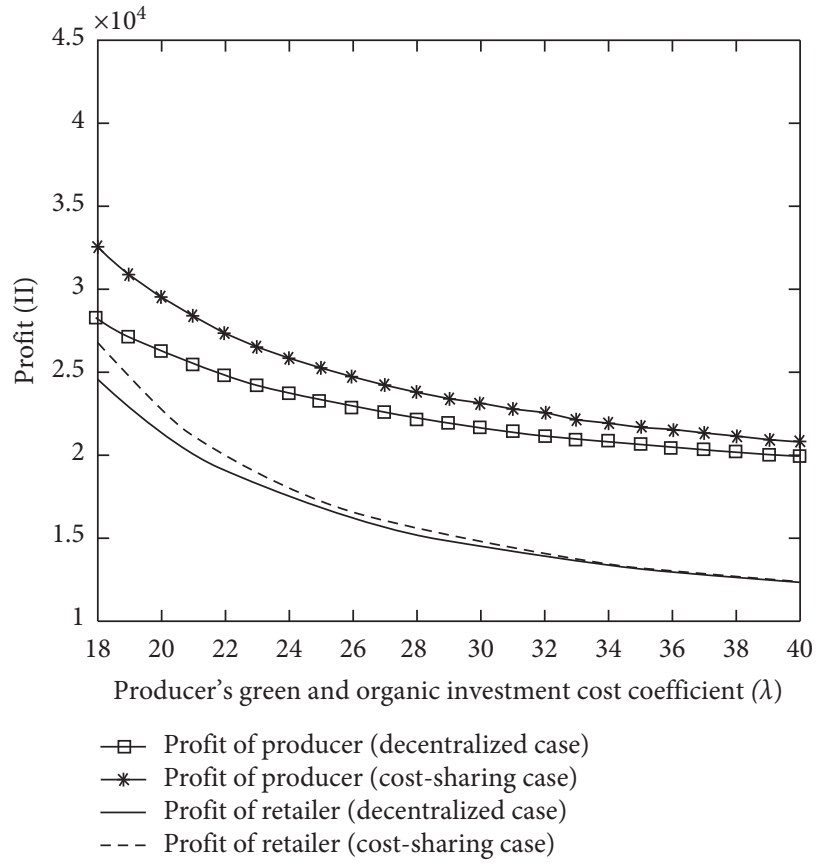

(c)

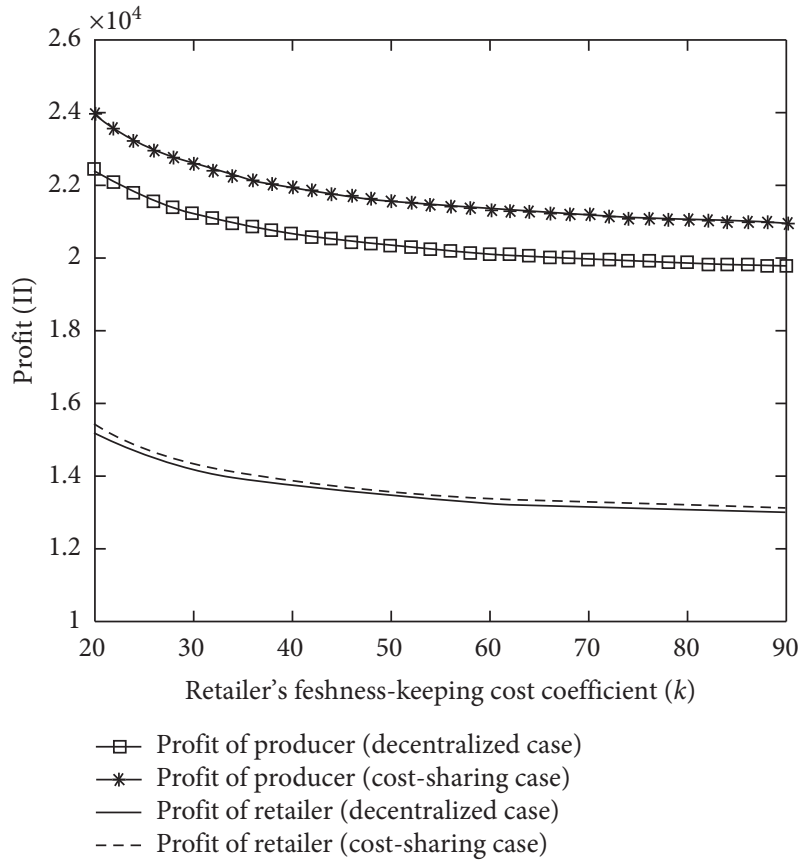

(d)

FIgURE 2: Impact of key parameters on individual profits in the APSC under different decision cases. (a) Individual profits vs. $\beta$. (b) Individual profits vs. $\tau$. (c) Individual profits vs. $\lambda$. (d) Individual profits vs. $k$.

4.4. Impact of Key Parameters on the Greenness Level $(\mu)$ under Different Cases. Figure 4 confirms the conclusions in Propositions 5, 6, and 8 on how the producer's effort in investing in greenness of the agricultural product is affected by the two demand-enhancing parameters $\beta$ and $\tau$ and the two quadratic cost parameters $\lambda$ and $k$. More specifically, a higher demand-enhancing parameter $\beta$ or $\tau$ motivates the producer to put more effort in producing greener and more organic product. Conversely, a higher quadratic cost parameter $\lambda$ or $k$ dampens the producer's effort in enhancing the greenness level of the agricultural product. In addition, across the three cases, the integrated case tends to yield the highest greenness level, followed by the cost-sharing case, and lastly the decentralized case. Another point revealed by these four subfigures is that the direct demand-enhancing and quadratic cost parameters $\beta$ and $\lambda$ tend to have more 


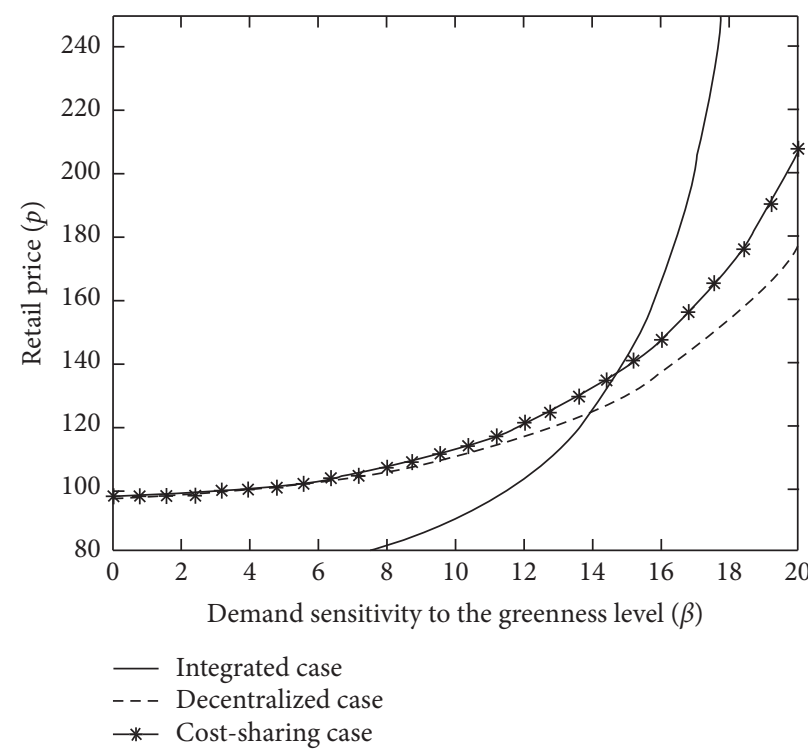

(a)

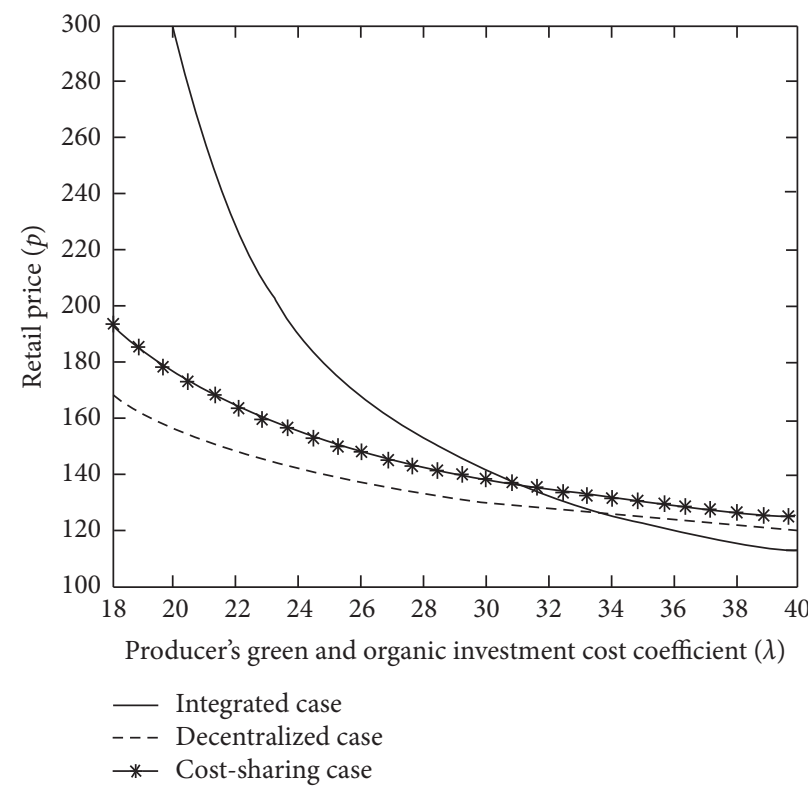

(c)

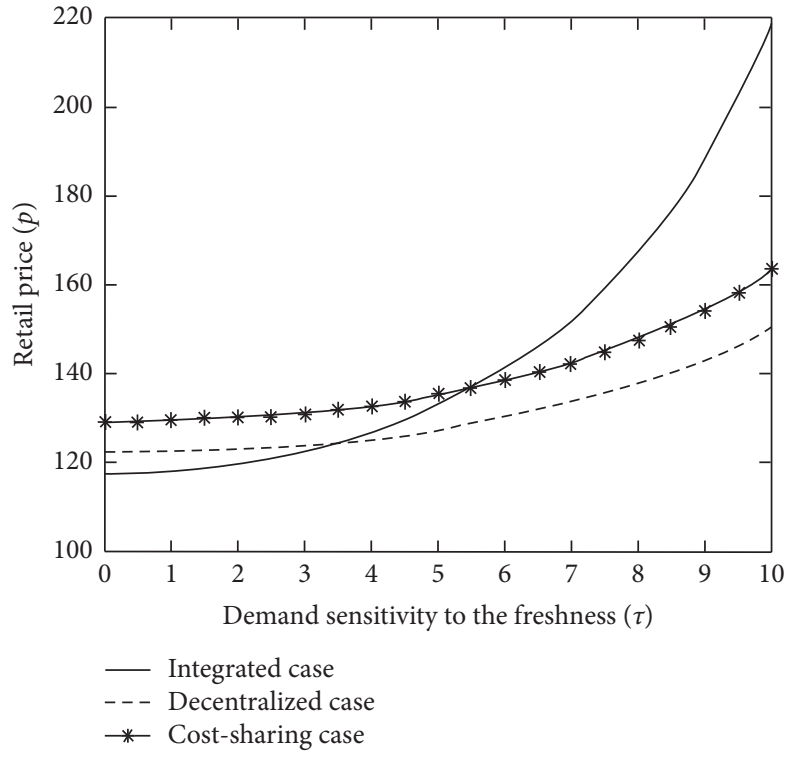

(b)

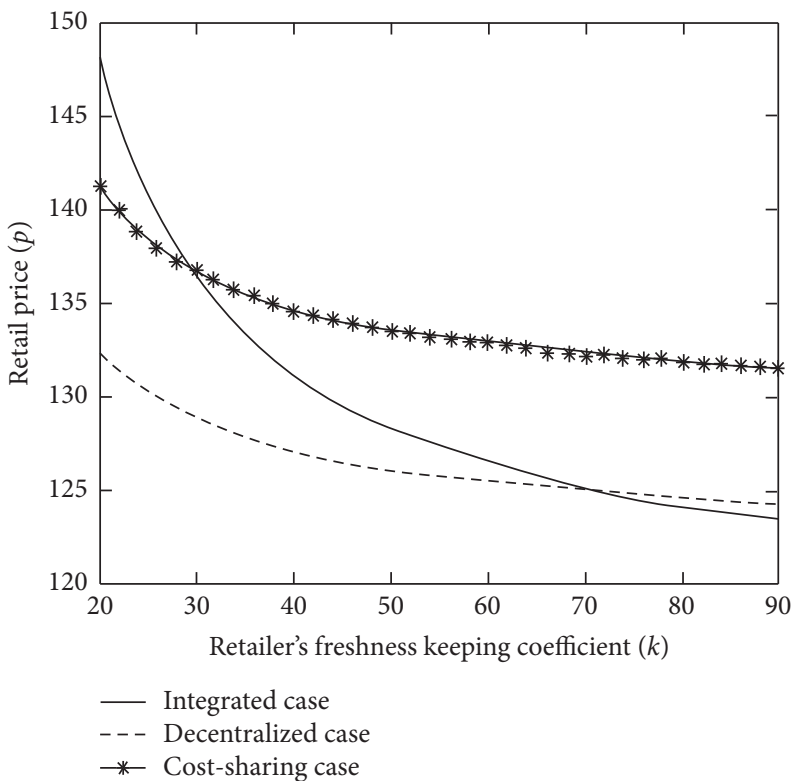

(d)

FIGURE 3: Impact of key parameters on the retail prices under different cases. (a) Retail prices vs. $\beta$. (b) Retail prices vs. $\tau$. (c) Retail prices vs. $\lambda$. (d) Retail prices vs. $k$.

dramatic impact on the producer's effort level than the indirect parameters $\tau$ and $k$ do.

The impact of key parameters on the freshness $(\theta)$ under different cases is similar to that of the greenness level $(\mu)$ under the same case. The figure and its analysis are also omitted.

4.5. Impact of the Cost-Sharing Proportion ( $\eta$ ) on Different Variables. When the retailer offers to share the producer's investment cost in improving the greenness level of the agricultural product, Figure 5(a) visually confirms the analytical result in Proposition 7. The cost-sharing serves as an effective incentive for the producer to improve the green (or organic) level of the agricultural product, and the spillover effect motivates the retailer to put more fresh-keeping effort. The higher the sharing ratio, the higher the two members' effort levels. Eventually, these enhanced effort levels lead to higher wholesale and retail prices. It is also worth noting that the greenness level curve is much steeper than the freshness level curve in Figure 5(a), implying that the retailer's costsharing initiative motivates the producer better than itself. 


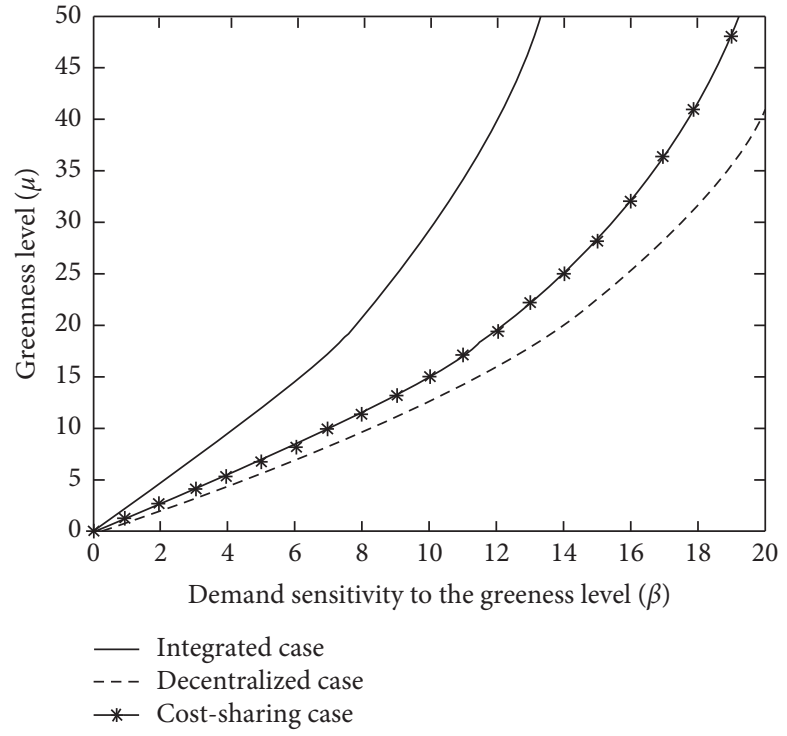

(a)

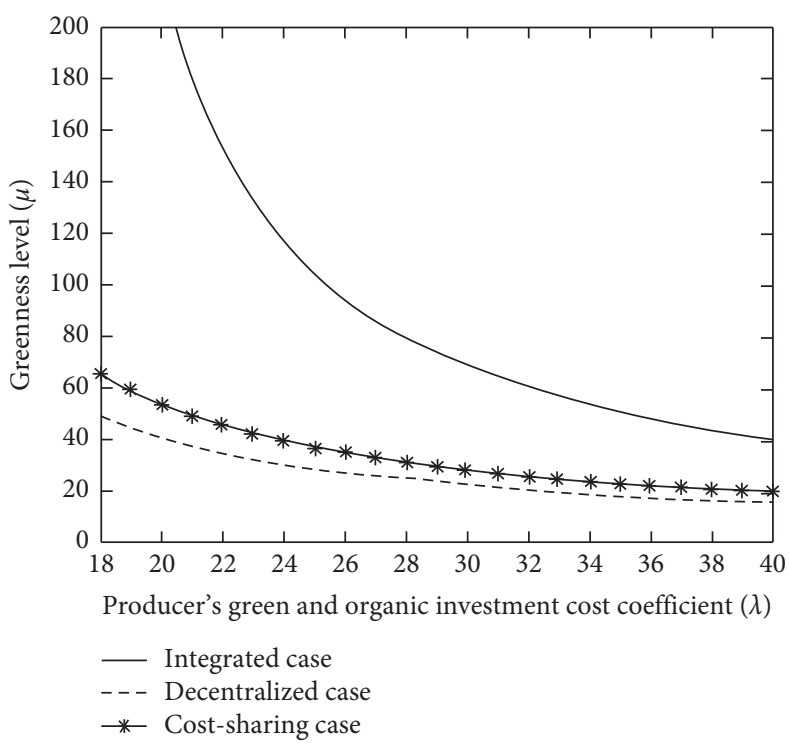

(c)

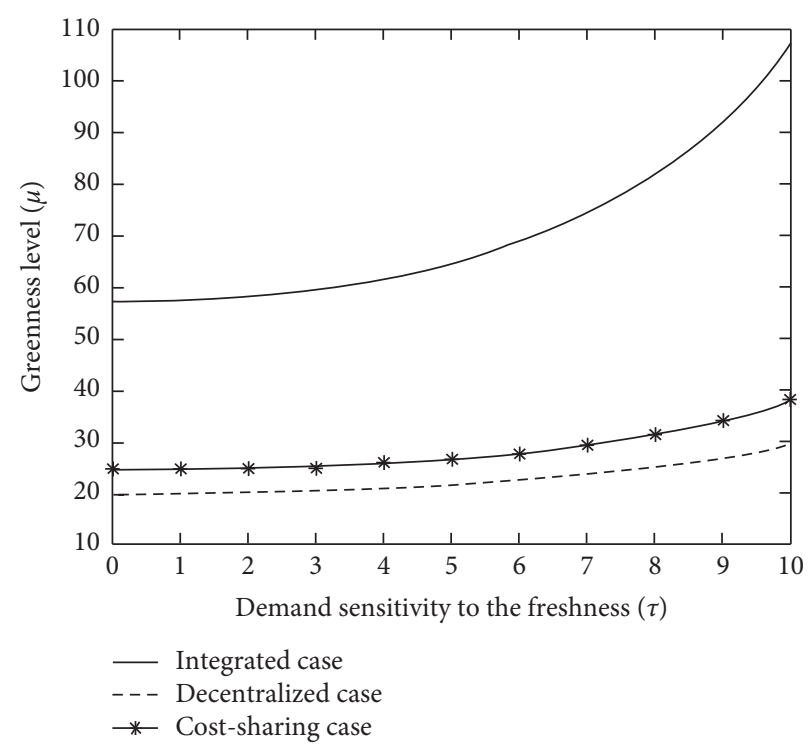

(b)

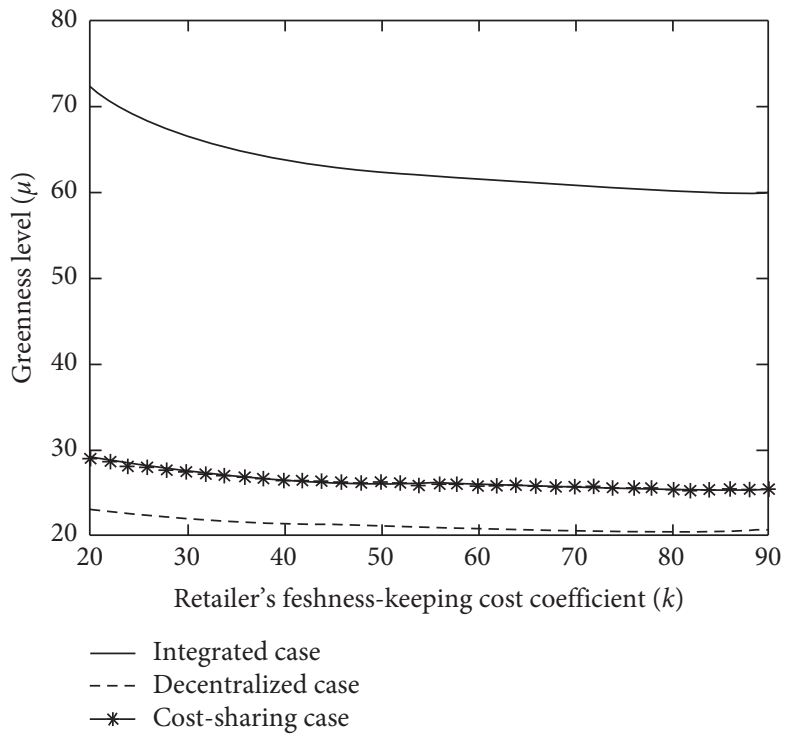

(d)

Figure 4: The impact of key parameters on the greenness level $(\mu)$ under different cases: (a) $\mu$ vs. $\beta$. (b) $\mu$ vs. $\tau$. (c) $\mu$ vs. $\lambda$. (d) $\mu$ vs. $k$.

For the more responsive producer, it always enjoys a higher profit at a higher cost-sharing ratio as established in Proposition 7 and visually displayed in Figure 1. However, the escalated retail price counterbalances enhanced demand due to higher greenness and freshness levels, thereby leading to lower profits for the retailer and the channel when the cost-sharing ratio continues increasing into an excessive territory as shown in Figure 1. Meanwhile, Figure 5(b) shows that the cost-sharing ratio $\eta$ of green (or organic) investment by the retailer is always conducive to the increase of demand for agricultural products. Obviously, combined with the analysis in Figure 1, it is impossible for retailers to share the producer's investment cost in improving the greenness level of the agricultural product without considering its own interests. Therefore, the effect of increasing the cost-sharing ratio $\eta$ on the promotion of demand is limited.

\section{Conclusions}

In this paper, we first propose a two-echelon APSC under the freshness and greenness concerns where the producer is solely responsible for the investment cost in improving the greenness level of the agricultural product and the retailer takes care its fresh-keeping cost. The equilibrium results are obtained for both decentralized and integrated cases under this base model. Next, a cost-sharing contract is proposed to 


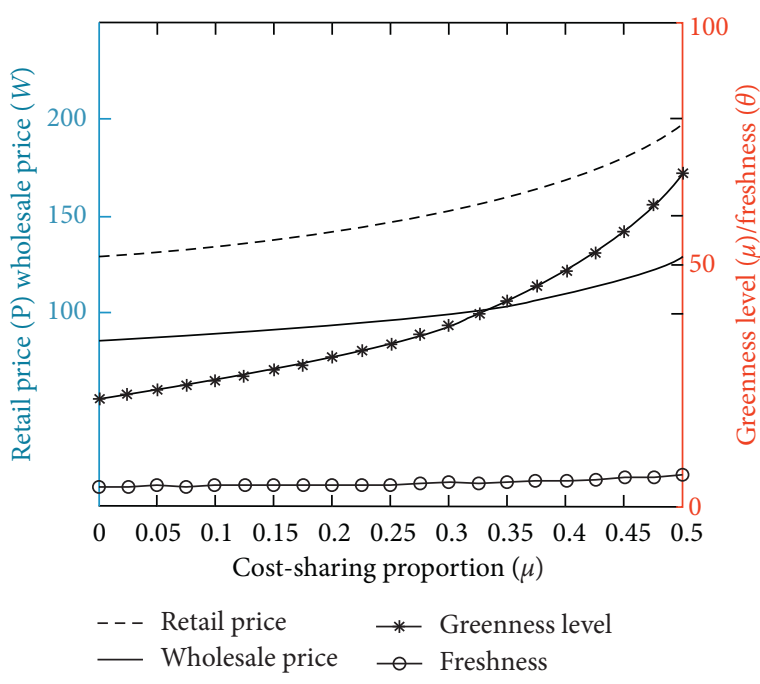

(a)

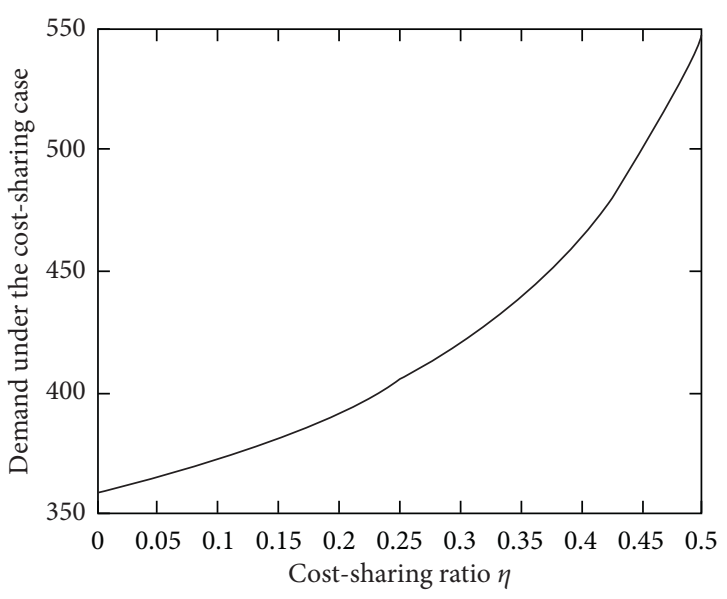

(b)

FIgURE 5: The impact of the cost-sharing proportion $(\eta)$ on the variables: (a) cost-sharing proportion $(\eta)$; (b) cost-sharing ration.

improve the performance of this supply chain, where the retailer offers to share a proportion of the producer's investment cost. After deriving the equilibrium results for the extended APSC model, we consider the impact of five main model parameters on the optimal decisions of the supply chain members and resulting profitability. Analytical results and numerical experiment show that equilibrium effort and pricing decisions and resulting profits increase in the two demand-enhancing parameters on the greenness and freshness attributes and decrease in the two quadratic cost parameters on these two attributes. It is also established that the producer as the Stackelberg leader always enjoys a higher profit than the retailer regardless of whether it shares the producer's greenness investment cost. When the costsharing proportion is within a limit, the retailer's costsharing initiative achieves a win-win profitability for both APSC members compared to the decentralized case without cost-sharing. In addition, our analysis indicates that the retailer's cost-sharing always enhances the channel profit compared to the case without cost-sharing (Proposition 2). However, this research also reveals a side effect of the retailer's cost-sharing: the profit gap between the two members will be further widened due to the retailer's follower position and additional expense.

The current research aims to better understand the operations of a two-echelon APSC with freshness and greenness concerns and examine how a cost-sharing contract can improve its operations. This study has its limitations as it is put under a deterministic setting and considers only a cost-sharing contract. In future research, it would be interesting to expand the scope by considering revenuesharing and the producer sharing the retailer's fresh-keeping cost as well as uncertain demand. In addition, the current research framework considers only one producer and one retailer in a two-echelon APSC, and it is a worthy topic to examine multiple suppliers and multiple retailers and extend the analysis to a dual (omni) channel structure.

\section{Data Availability}

The data used to support the findings of this study are available from the corresponding author upon request.

\section{Conflicts of Interest}

All the authors declare that they have no conflicts of interest.

\section{Acknowledgments}

This work was supported by the National Natural Science Foundation of China (71672013) and Sichuan Philosophy and Social Science Key Research Base: Funded Project of Sichuan Mineral Resources Research (SCKCZY2019-YB008 and SCKCZY2019-ZC004).

\section{References}

[1] J. Wang and Q. Jia, "Research on the cost allocation of joint distribution of agricultural products based on game theory," Advance Journal of Food Science and Technology, vol. 5, no. 8, pp. 1105-1109, 2013.

[2] B. Chen and A. Zhou, "An analysis of the cold chain logistics concerning agricultural products in Chongqing city," Asian Agricultural Research, vol. 8, no. 1, pp. 19-21, 2016.

[3] Y. X. Zhu, S. J. Lee, J. Zhang, and J. Q. Zhang, "Performance evaluation on supplier collaboration of agricultural supply chain," International Journal of Information Systems and Change Management, vol. 8, no. 1, pp. 23-36, 2016.

[4] S. M. S. Islam and M. A. Hoque, "A joint economic lot size model for a supplier-manufacturer-retailers supply chain of an agricultural product," Opsearch, vol. 54, no. 4, pp. 868-885, 2017.

[5] Q.-J. Jiang, M.-Z. Jin, and P.-Y. Ren, "Mathematical analysis of the impact mechanism of information platform on agroproduct supply chain and agro-product competitiveness," Open Physics, vol. 15, no. 1, pp. 108-120, 2017.

[6] Y. Fang, Y. Jiang, L. Sun, and X. Han, "Design of green cold chain networks for imported fresh agri-products in Belt and 
Road development," Sustainability, vol. 10, no. 5, p. 1572 , 2018.

[7] X. Su, H. Liu, S. Hou, and H. Liu, "The trilateral evolutionary game of agri-food quality in farmer-supermarket direct purchase: a simulation approach," Complexity, vol. 2018, Article ID 5185497, 11 pages, 2018.

[8] K. Leng, L. Jin, W. Shi, and I. Van Nieuwenhuyse, "Research on agricultural products supply chain inspection system based on internet of things," Cluster Computing, vol. 22, no. S4, pp. 8919-8927, 2019.

[9] L. Liu and X. Zhan, "Analysis of financing efficiency of Chinese agricultural listed companies based on machine learning," Complexity, vol. 2019, Article ID 9190273, 11 pages, 2019.

[10] X. Q. Cai, J. Chen, and Y. B. Xiao, "Optimization and coordination of fresh product supply chains with freshnesskeeping effort," Production \& Operations Management, vol. 19, no. 3, pp. 261-278, 2010.

[11] J. An, L. Wang, and X. Lv, "Research on agri-food cold chain logistics management system: connotation, structure and operational mechanism," Journal of Service Science and Management, vol. 08, no. 06, pp. 894-902, 2015.

[12] H. Yang, D. Wang, J. Zhang, and J. Li, "Game analysis on product safety input of fresh agricultural supply chain upstream," Liss 2014, vol. 2015, pp. 1613-1619, 2015.

[13] Q. Zheng, P. Ieromonachou, T. Fan, and L. Zhou, "Supply chain contracting coordination for fresh products with freshkeeping effort," Industrial Management \& Data Systems, vol. 117 , no. 3, pp. 538-559, 2017.

[14] B. Yan, J. Wu, Z. Jin, and S. He, "Decision-making of fresh agricultural product supply chain considering the manufacturer's fairness concerns," 4Or, vol. 18, no. 1, pp. 91-122, 2020.

[15] M. Wang, L. Zhao, and M. Herty, "Modelling carbon trading and refrigerated logistics services within a fresh food supply chain under carbon cap-and-trade regulation," International Journal of Production Research, vol. 56, no. 12, pp. 4207-4225, 2018.

[16] A. Liu, Y. Xiao, X. Ji et al., "A novel two-stage integrated model for supplier selection of green fresh product," Sustainability, vol. 10, no. 7, p. 2371, 2018.

[17] X. Ma, S. Wang, S. M. N. Islam, and X. Liu, "Coordinating a three-echelon fresh agricultural products supply chain considering freshness-keeping effort with asymmetric information," Applied Mathematical Modelling, vol. 67, pp. 337-356, 2019.

[18] B. Yan, X. Chen, Q. Yuan, and X. Zhou, "Sustainability in fresh agricultural product supply chain based on radio frequency identification under an emergency," Central European Journal of Operations Research, vol. 2019, pp. 1-19, 2019.

[19] B. Yan, G. Liu, Z. Zhang, and C. Yan, "Optimal financing and operation strategy of fresh agricultural supply chain," Australian Journal of Agricultural and Resource Economics, vol. 64, no. 3, pp. 776-794, 2020.

[20] H. Zhang and Y. Cui, "A model combining a Bayesian network with a modified genetic algorithm for green supplier selection," Simulation, vol. 95, no. 12, pp. 1165-1183, 2019.

[21] H. Cui, T. Zhao, and P. Tao, "Evolutionary game study on the development of green agriculture in China based on ambidexterity theory perspective," Polish Journal of Environmental Studies, vol. 28, no. 3, pp. 1093-1104, 2019.

[22] H. Huang, J. Zhang, X. Ren, and X. Zhou, "Greenness and pricing decisions of cooperative supply chains considering altruistic preferences," International Journal of Environmental Research and Public Health, vol. 16, no. 1, p. 51, 2019.
[23] D. Ghosh and J. Shah, "A comparative analysis of greening policies across supply chain structures," International Journal of Production Economics, vol. 135, no. 2, pp. 568-583, 2012.

[24] D. Ghosh and J. Shah, "Supply chain analysis under green sensitive consumer demand and cost sharing contract," International Journal of Production Economics, vol. 164, pp. 319-329, 2015.

[25] Z. Liu, K. W. Li, B.-Y. Li, J. Huang, and J. Tang, "Impact of product-design strategies on the operations of a closed-loop supply chain," Transportation Research Part E: Logistics and Transportation Review, vol. 124, pp. 75-91, 2019.

[26] K. Ehsan, A. Tayyebeh, E. Ahmad, and T. Jolanta, "The effect of green supply chain management practices on environmental performance and competitive advantage: a case study of the cement industry," Technological and Economic Development of Economy, vol. 22, no. 2, pp. 293-308, 2016.

[27] L. Cui, S. Guo, and H. Zhang, "Coordinating a green agri-food supply chain with revenue-sharing contracts considering retailers' green marketing efforts," Sustainability, vol. 12, no. 4, p. 1289, 2020.

[28] A. Sacco and P. De Giovanni, "Channel coordination with a manufacturer controlling the price and the effect of competition," Journal of Business Research, vol. 96, pp. 97-114, 2019.

[29] D. Ni, K. W. Li, and X. Tang, "Social responsibility allocation in two-echelon supply chains: insights from wholesale price contracts," European Journal of Operational Research, vol. 207, no. 3, pp. 1269-1279, 2010.

[30] P. Ma, K. W. Li, and Z.-J. Wang, "Pricing decisions in closedloop supply chains with marketing effort and fairness concerns," International Journal of Production Research, vol. 55, no. 22, pp. 6710-6731, 2017.

[31] X.-X. Zheng, Z. Liu, K. W. Li, J. Huang, and J. Chen, "Cooperative game approaches to coordinating a three-echelon closed-loop supply chain with fairness concerns," International Journal of Production Economics, vol. 212, pp. 92-110, 2019. 